\title{
Epistemic norms, closure, and No-Belief hinge epistemology
}

\author{
Mona Simion $^{1}$ (D) Johanna Schnurr ${ }^{2} \cdot$ Emma Gordon $^{3}$
}

Received: 17 November 2018 / Accepted: 26 February 2019 / Published online: 2 March 2019

(c) The Author(s) 2019

\begin{abstract}
Recent views in hinge epistemology rely on doxastic normativism to argue that our attitudes towards hinge propositions are not beliefs. This paper has two aims; the first is positive: it discusses the general normative credentials of this move. The second is negative: it delivers two negative results for No-Belief hinge epistemology such construed. The first concerns the motivation for the view: if we're right, doxastic normativism offers little in the way of theoretical support for the claim that our attitudes towards hinge propositions are anything but garden-variety beliefs. The second concerns theoretical fruitfulness: we show that embracing a No-Belief view will either get us in serious theoretical trouble, or loose all anti-sceptical appeal.
\end{abstract}

Keywords Hinge epistemology $\cdot$ Closure $\cdot$ Epistemic norms $\cdot$ Scepticism

\section{Introduction}

There's a new kid on the hinge epistemology block: the No-Belief view. ${ }^{1}$ No-Belief claims that our propositional attitudes towards hinge propositions, ${ }^{2}$ such as 'I'm not

\footnotetext{
${ }_{1}^{1}$ This paper will mostly focus on Pritchard's formulation of the view; however, most things said here apply mutatis mutandis to no-belief views more generally. As we note, however, it's important to distinguish Pritchard's No-Belief view from stronger positions about hinges that trivially get the result that hinges are not beliefs by maintaining that hinges are non-propositional.

2 We will, for the purpose of this paper, only focus on what is usually referred o in the literature as 'uber-hinges,' i.e. 'I am not radically deceived,' 'The external world exists,' etc.
}

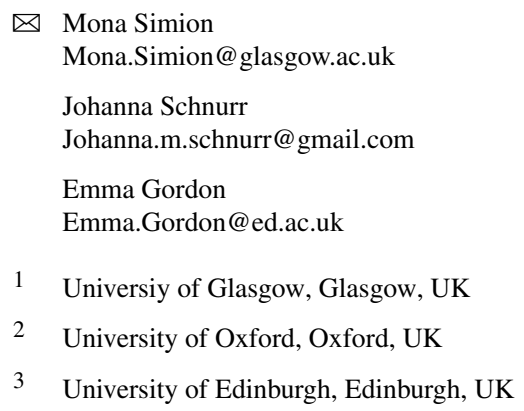


radically deceived,' 'There is an external world' etc., although phenomenologically very similar to beliefs, are actually non-doxastic propositional attitudes, i.e. mere 'commitments.'

This theory entails substantial fallibility in our self-ascription of attitudes: the propositions classified as hinges are ones many of us take ourselves to believe. Why should we buy into this error theory?

No-Belief defenders rely heavily on doxastic normativism in order to answer this question. Very roughly, according to doxastic normativism, part of what makes an attitude a belief rather than another type of attitude is that it is governed by an epistemic norm. For instance, Pritchard's (2015) answer to this question is developed in two stages: one negative, the other positive. The negative stage of the argument ${ }^{3}$ maintains, first, that hinge commitments are not, as Pritchard puts it, 'in the market' for rationally grounded knowledge, in virtue of not being responsive to rational consideratons.

$\mathrm{At}^{4}$ this juncture, Pritchard offers his positive argument for thinking hinges are not in fact beliefs, despite our attitudes toward hinges bearing (many) superficial similarities to beliefs. His argument—call this the No Belief Hinges Argument—proceeds as follows:

\section{No-Belief hinges argument}

(1) Doxastic Responsiveness (DR): Necessarily, a mental state is a belief only if it is responsive to rational considerations.

(2) Hinge Non-Responsiveness (HNR): Hinge commitments are not responsive to rational considerations.

(3) No-Belief hinges (NBH) Hinge commitments are not beliefs

The broad idea here is that hinge commitments supposedly differ from beliefs in their responsiveness to rational considerations, and this difference suffices to classify them as a separate type of attitude. Doing so is meant to have significant theoretical benefits - not only advantages over the other ways of characterising hinges, but also more generally in showing a way in which a hinge epistemology can be used as a powerful weapon against closure-based sceptical arguments. ${ }^{5}$

For our purposes, we will remain neutral on the merits of these wider ambitions for a Wittgenstenian epistemology. Instead, we are going to focus on assessing the normative credentials of relying on doxastic normativism to argue that our attitudes

\footnotetext{
3 This is developed primarily in the first half of his 2016, Ch. 3.

4 For if they were, he claims, then we wouldn't be able to make sense of the kind of reasoning licensed by closure style inferences; The two main kinds of proposal Pritchard criticises on these grounds, and which maintain that hinges are knowledge-apt, are the externalist and entitlement treatments of hinges, respectively. However, he claims — and this is the second part of his negative argument — that what accounts for why hinges are not in the market for rationally grounded knowledge is not that they are non-propositional, as some commentators have supposed. See, for example, Moyal-Sharrock (2013). Such a view carries with it its own serious problems.

Fortunately, as Pritchard's sees it, one can sidestep both (i) problems to do with closure and at the same time, (ii) problems that are incurred by avoiding closure problems by 'going non-propositional', by opting for a middle view according to which hinges aren't in the market for rationally grounded knowledge not because they're non-propositional, but rather, because they're not beliefs.

5 Though, for Pritchard, the resources of disjunctivism (e.g., McDowell 1996) are needed if we are to satisfactorily respond to underdetermination-based scepticism. This point, however, will not concern us in the present paper.
} 
towards hinge propositions are not beliefs. In this, while the paper closely discusses this particular variety of hinge epistemology—i.e., No-Belief hinge epistemology-our results generalise to any attempt to draw an inference from doxastic normativism to a view that hinge commitments do not qualify as beliefs proper. Furthermore, one important novel contribution this paper is making is bringing three debates together, i.e. debates about the norm of belief, the nature of belief and debates in hinge epistemology.

To this effect, in order to achieve the appropriate degree of generality, we will restrict our focus to foundational hinge propositions that widely recognised as such by hinge literature, i.e. what is commonly referred to as 'uber-hinges' (such as 'I am not radically deceived,' 'The external world exists'). Firstly, we show that formulating the argument for NBH in a satisfactory way is not as easy as it may look. We discuss some interpretations of the premises on which the argument does not come out sound, and then propose a weaker, normative, reading that looks more promising. We then present a counterexample to this normative argument. We finish by discussing an alternative way to construe the normativity at hand in the HNR premiss, but conclude that this refurbished version of No-Belief fails too.

Here is the game plan: we first look closer at and refine DR and HNR to get at what we take to be the most charitable interpretation of the view (Sect. 2). Then, we put forth a case of radical deception that creates trouble for HNR (Sect. 3). In Sect. 4, we embark on a rescue mission on behalf of No-Belief. We end on a pessimistic note concerning both Pritchard's version of the view, and, more generally, the prospects for this approach to hinge epistemology.

\section{Is rational evaluation of hinge commitments impossible?}

Here is Pritchard motivating DR:

[T]here are certain minimal, but constitutive nonetheless, connections between belief and truth such that a propositional attitude that didn't satisfy them simply would not count as a belief, but would be a different propositional attitude entirely. In particular, it makes no sense, for example, for there to be an agent who believes that $\mathrm{p}$ while taking herself to have no reason whatsoever for thinking $\mathrm{p}$ to be true. A fortiori, it does not make sense for an agent to believe that $\mathrm{p}$ while taking herself to have overwhelming reasons for thinking that $\mathrm{p}$ is false (90).

Now, let's have a closer look at the above motivation for DR. In what way is it that 'it does not make sense for there to be an agent who believes that p' and at the same time takes herself to 'have no reason whatsoever for thinking $\mathrm{p}$ to be true?' DR can be read as either a psychological or as a conceptual claim ${ }^{6}$. Pritchard cites no empirical

\footnotetext{
${ }^{6}$ It is worth noting that there is at least one line of thought according to which DR fails on either kind way of interpreting DR. The line of argument proceeds as follows. According to error theorists about epistemic reasons, there are no epistemic reasons for belief (see Olson 2011). There is at least one epistemic error theorist-Jonas Olsson - and he has at least one belief. Therefore, contrary to what Pritchard is suggesting, it it does make sense (in that it is at least possible) for there to be an agent who believes something and at the same time takes herself not to have any (epistemic) reason for believing that proposition. For critical
} 
evidence for DR, so the psychological interpretation seems unlikely. Furthermore, a merely psychological claim would not suffice for his ends, since he does not need to merely show that current human believers happen to not be capable of non-responsive beliefs, but that nothing functioning as a hinge could ever be a belief. The conceptual reading therefore makes the most sense.

There are two notions of reason-responsiveness that Pritchard could have in mind as a necessary condition on belief. The stronger one would be an etiological property: having been caused in response to reasons. The weaker one would be a dispositional property of sensitivity to reasons. The former idea, that all beliefs are caused in response to reasons, is highly implausible. Beliefs may come about through hypnosis or knocks on the head, they may be caused by bias or hasty heuristics. Pritchard gives us no reason to think that such beliefs should be conceptually impossible: he merely pushes the intuition that mental states that persist despite being considered rationally unfounded by the subject are not beliefs. The second, weaker notion of reason-responsiveness then would be that beliefs need to be such that were the subject to perceive reasons against them, confidence would be affected-the subject would either weaken her credence in the relevant proposition, or, alternatively, abandon belief altogether. This has more plausibility (although we do not endorse it either) and is furthermore similar to rationality constraints on belief that have been endorsed by other authors. $^{7}$

Let us for the sake of argument grant this dispositional reading of DR. The argument for NBH will nevertheless not work. To see why, we need to say something about HNR, the principle about hinge commitments that DR is supposed to work with.

Why should we believe that HNR - in this descriptive form-holds, that is, that hinge commitments are not responsive to rational considerations? In support of HNR, Pritchard's answer relies on the Wittgensteinian (OC 114, 138) claim that one cannot doubt one's hinge commitments, or the epistemic “door wouldn't turn." He suggests that rational evaluation of hinge commitments is impossible (90). Now, of course the equivalence between HNR and the Wittgensteinian claim is far from obvious: after all, it's possible for something $X$ to be evaluable from a point of view $P$, in spite of the fact that $\mathrm{X}$ does not respond to P-generated reasons. And the other way around: it can be that something $\mathrm{X}$ responds to P-generated reasons even though it shouldn't, because evaluating $\mathrm{X}$ from point of view $\mathrm{P}$ is not permissible. ${ }^{8}$ We take it, though, on a maximally charitable reading, that what Pritchard has in mind is something like the following: hinges are not the proper subject of rational evaluation, which

\footnotetext{
Footnote 6 continued

discussion of epistemic error theory, and some puzzles that arise for those who accept the position, see Streumer (2013).

7 Glüer and Wikforss (2009) have claimed that there is a limit to the amount of irrationality beliefs can have, Shah and Velleman (2005) write "According to our analysis of the concept, one may apply the norm of truth to a cognition by classifying it as a belief only if it is in fact regulated for truth to some extent, as if it were being held to the same norm by the subject himself. Hence, the descriptive aspect of the concept forbids one to apply it, with its implicit norm, to any cognition toward which the subject doesn't behave as if he were applying that norm." Wedgwood (2009) has linked the ability to believe to possession of a minimum of rational dispositions.

8 Thanks to an anonymous referee for pointing this out.
} 
is why they are also not responsive to reasons. Now, crucially, "rational evaluation" is ambiguous between evaluation (for rationality, epistemic permissibility etc.) in a rational manner and mere evaluation for rationality. Pritchard may have a case for the impossibility of the former when it comes to hinge commitments, but not for the impossibility of the latter. The reason he gives us for the impossibility of rational evaluation is that any premiss one could use on the basis of which to rationally doubt a hinge commitment would necessarily be less certain than the hinge itself - a point that follows from Wittgenstein's account of the structure of rational support relations. The hinges are supposed to be the enabling conditions-as opposed to the objects of - rational evaluation, so any attempt to evaluate the rational standing of a hinge would fail to be rational.

Such attempts, irrational or not, are however clearly possible. The sufferer of paranoid delusions, considering the possibility that all his limbs are prosthetics put in place by his foes, can ask himself "Is it rational to continue believing I have hands despite what the voices tell me?". The impressionable teenage moviegoer who mistook The Matrix for a documentary can ask herself "Is it rational to believe the world as I think of it exists?". Both of these are instances of evaluating a hinge commitment for rationality. Pritchard may be right that both are irrational, perhaps even that anyone entering into such evaluations is not only irrational but "unhinged", plunged into cognitive chaos by their evaluations run amok, but all of that is only evidence for the impossibility of evaluating a hinge commitment in a rational manner, not for the impossibility of evaluating it for rationality.

It is worth considering that Pritchard might nonetheless press back at this juncture by appealing to Wittgenstein's famous 'river bed' passages from On Certainty, which proceed as follows:

It might be imagined that some propositions, of the form of empirical propositions, were hardened and functioned as channels for such empirical propositions as were not hardened but fluid; and that this relation altered with time, in that fluid propositions hardened, and hard ones became fluid.

The mythology may change back into a state of flux, the river-bed of thoughts may shift. But I distinguish between the movement of the waters on the river-bed and the shift of the bed itself; though there is not a sharp division of the one from the other...

And the bank of that river consists partly of hard rock, subject to no alteration or to only an imperceptible one, partly of sand, which now in one place now in another gets washed away, or deposited. (OC, §§96-99)

Pritchard thinks the lesson to draw from Wittgenstein's river-bed analogy is that some hinges are 'shiftable'. He says:

This manner of describing our hinge commitments dovetails with the idea that while such commitments might change over time, these changes are entirely at the periphery and the rate of change is inevitably slow $(2015,97)$

Suppose, for the sake of argument, we grant Pritchard the descriptive claim, motivated by the river-bed passage, that (at least some) hinges can lose their status as hinges over time. With this point in hand, we might now imagine that Pritchard could press 
back as follows: cases where it seems as though hinges are evaluated for rationality are (as this line of thought goes) better described as cases where the proposition under consideration is no longer a hinge for that individual. For instance, in the case where someone (suffering from paranoid delusions) considers the possibility that all her limbs are cleverly disguised prosthetics, the proposition that she has hands is no longer a hinge for her. And accordingly, in asking whether it is rational to continue believing she has hands, she is not actually evaluating a (genuine hinge) for rationality.

This kind of an anticipated reply, however, actually runs into problems under closer inspection. The very idea that some hinges are shiftable over time, and are accordingly such that they can lose their status as hinges, calls for some explanation. By what mechanisms could a hinge ever-even if very slowly-begin to lose its status as a hinge? Note that whatever the answer to this question, it needs be such that the shift cannot happen in virtue of the relevant attitude's being evaluated for rationality. This constraint, however, seems ad-hoc: It's hard to see how any plausible answer could exclude scenarios in which evaluating the hinge for rationality plays some causal role. However, if that's right, then we are back to thinking that the kind of cases offered count against the impossibility of evaluating hinges for rationality.

In sum, then, here is where we are with respect to the responsiveness of hinges: Neither route to argue for NBH from a descriptive principle about belief works. Arguing that beliefs necessarily originate as responses to rational considerations, whilst hinges do not, fails because the premiss about beliefs is false. Arguing that beliefs are necessarily disposed to react to some types of rational evaluation and that hinge commitments are not fails because the premiss about hinge commitments is false. We need a different way to construe the argument for NBH.

The conclusion we came to above about HNR points to a more promising strategy. Instead of contrasting hinges and beliefs descriptively, we should contrast them normatively. Hinges are never an appropriate object of rational evaluation, meaning that they ought not to respond to being thusly evaluated. Beliefs on the other hand are such that they ought to respond in certain ways to specific prompts of rational evaluation, such as consideration of evidence against their content. Here is a normative version of the argument for No-Belief:

(1) nDR: Beliefs are necessarily such that they ought to be responsive to rational considerations.

(2) nHNR: Mental states towards hinge propositions are not such that they ought to be responsive to rational considerations.

(3) NBH: Mental states towards hinge propositions are not beliefs (from (1) and (2)).

In what follows, we will evaluate this normative argument for the No-Belief view, which we take to be the most charitable formulation. Importantly, though, all points we will be making against No-Belief thus construed apply, mutatis mutandis, to No-Belief construed along DR and HNR lines.

\section{Can hinge commitments change over time?}

Consider the following case: 
TWO LONDONS: (t1) George is just another unhappy middle-aged guy living in the suburbs of London. He has a terribly boring job-has been working as an accountant for his uncle's car repair shop for his entire life- his marriage didn't go that well, and he hardly ever gets to see his kids. Nothing exciting ever happens to George. One morning, George wakes up in a completely unfamiliar place (t2): he's lying in a luxurious bed in a five star hotel in centre London. He tries to leave the place in order to figure out what is going on, only to discover that everyone he meets on the way out not only knows his name, but is also strangely keen to shake his hand. As soon as he's out in the street, people around him shout his name excitedly and ask him for autographs. Scared to death, George goes back to the hotel lobby and asks the receptionist how he got there. After long and tiresome chats with everyone around him, it turns out that George is a famous movie star, his career could not go any better, he has a wonderful partner and a teenage son that love him very much. Now, of course, George does not believe a word of what he's being told. After several months of uninterrupted movie star-appearances (t3) however, he starts thinking that maybe his old life was just a bad dream. Fifteen years go by, until one morning (t4) he wakes up in his old bed in the suburbs, where not much is changed from the way things seemed to be at $\mathrm{t} 1$. Everyone George talks to about his experiences of the past fifteen years reacts with disbelief and after a while George gives up on trying to convince them. He never quite settles back however into his old beliefs about the nature of his environment, the reliability of his faculties, and the trustworthiness of those around him. He takes seriously the possibility that he may be radically mistaken about whether things around him are as they appear to be, but is wearily inclined towards thinking he is not, and that the mistake instead lies with his previous acceptance of the movie star episode. After two years in this uneasy state, George wakes up in his movie star environment once again(t5).

Now, George subjects his commitment to not being radically deceived to serious evaluation, and this time, his commitment actually wavers. The question now is what the normative status of this response to evaluation is. It seems clear that given his history of appearances, George is permitted to respond the way he does. Yet furthermore, it seems that if at $\mathrm{t} 5$ at the latest George were not to undergo some confidence lowering about the veracity of appearances, he would be in breach of epistemic rationality. He ought to lower his confidence that he is not radically mistaken in light of his perceived evidence.

What TWO LONDONS shows is that there are cases where hinge commitments ought to respond to rational evaluation. nHNR is false, and the argument for $\mathrm{NBH}$ consequently fails.

\section{No-Belief and epistemic norms}

We will now consider a possible defence of nHNR against the TWO LONDONS counterexample. Here is one way in which one could think No-Belief could be saved, which also seems to fit nicely with the Wittgensteinian motivations behind it: maybe the argument above is ambiguating on the relevant epistemic 'ought.' After all, in line with general normativity, epistemic normativity does not generate one and only one 
normative constraint. Let's take a simple teleo-normative framework in order to easily illustrate what we have in mind. Take prudential normativity: Mary is prudentially permitted, for instance, to take Euston Road in order to reach King's Cross if, e.g., Euston Road leads to King's Cross, she looked on the map and it seems to be the right way there, she is very tired and it's the shortest way there etc. Conversely, Mary is not prudentially permitted to take, say, Champs Elysee in order to reach King's Cross (granted that she's not very cleverly deceived into thinking that's the right way to King's Cross).

There is, however, a different way in which Mary can be prudentially permitted to take Champs Elysee in order to go to Kings's Cross, as weird as that may seem, and even if she knows full well that this road is never going to get her there: if the evil prudential fairy makes her taking Champs Elysee a precondition for any further prudential gain. Let us call this 'primary permissibility,' to distinguish it from its everyday counterpart. It is primarily prudentially permissible for Mary to take Champs Elysee to King's Cross, because otherwise there are no more prudential goods available to her.

Epistemic normativity works in similar ways: I am not epistemically justified-i.e. permitted - to believe that there's a pink elephant eating ice-cream in my office right now. However, if there's an epistemic consequentialist evil fairy who, were I not to form this belief, would make sure to mislead me for the rest of my epistemic life, such that no knowledgeable/true beliefs would ever be within my reach again, I am epistemically permitted (albeit in a different sense, i.e. mapping on to a different normative constraint that does not talk about knowledge-generating justification) to form the pink elephant belief. ${ }^{9}$ I have primary permissibility to believe there's a pink elephant in my office because otherwise I will be kicked out of the land of epistemic goods altogether.

To go back to No-Belief: at first glance, one (Wittgenstein-friendly) way to save the view could go along the following lines: hinges are commitments rather than beliefs in that they enjoy a different type of epistemic permissibility, i.e. not the type that maps on to garden variety knowledge-generating justification. After all, what the hinge metaphor suggests is that we could not even begin to embark on epistemic endeavours to begin with if it were not for being committed to hinges. As such, even though it may well be that there are defeaters lying around-like in TWO LONDONS -, which make it the case that hinge commitments don't enjoy knowledge-generating justification, they still preserve epistemic permissibility in this second, primary, sense. Here is Wittgenstein:

If you are not certain of any fact, you cannot be certain of the meaning of your words either [...] If you tried to doubt everything you would not get as far as doubting anything. The game of doubting itself presupposes certainty (OC 114-115). [..] If I want the door to turn, the hinges must stay put (OC 343).

The very possibility of inquiry, then, depends on commitments to hinges: this is why being committed to them is epistemically permissible even if not justified in the knowledge-generating sense. On this view, then, TWO LONDONS' George is

\footnotetext{
9 Of course, one disanalogy with the action case is that voluntarism about belief is thought by many to be implausible, so I might just not be able to do it. Since permissible does not imply can, however, this does not affect the argument above.
} 
not justified, but is primarily epistemically permitted to believe that he's not being radically deceived. As such, HNR can be saved: Hinge commitments ought not be responsive to rational considerations, in the sense in which they should be maintained even in the face of defeaters, due to enjoying primary epistemic permissibility. Call this 'the refurbished No-Belief view.'

It should be noted that this way of construing the permissibility of George's hinge commitment to the general veracity of his appearances differs from another type of hinge epistemology, which is one of the main rivals of Pritchard's No-Belief account: an epistemic hinge or alternatively 'cornerstone' epistemology like Crispin Wright's. ${ }^{10}$ According to Wright, hinge commitments are beliefs that enjoy a particular type of entitlement, i.e. entitlement generated by the fact that, without these commitments, we would be prevented from embarking in inquiry altogether. ${ }^{11}$ Wright's entitlement, thus, is similar to what we have dubbed primary permissibility. Wright however considers entitlements knowledge-generating, whereas the permissibility of staying committed to hinges one has rational grounds to doubt would not be knowledge-generating, but concern another kind of epistemic normativity. This makes for a significant difference between the accounts. On Wright's view, knowledge is closed under known entailment. Warrant transmission, however, suffers exceptions: my warrant for believing there is a table in front of me fails to transmit to the known entailment that I'm not being radically deceived: the two beliefs in question enjoy different types of warrant. On the refurbished No-Belief view, in contrast, both the closure principle for knowledge and universal warrant transmission hold: the commitments enjoying what we have dubbed 'primary epistemic permissibility' are not beliefs to begin with, so they are not the proper target of these principles. If one thinks we should better try to preserve both closure and transmission unrestrictedly, this thus gives one a reason to prefer refurbished No-Belief over Wright's view.

Unfortunately, refurbished No-Belief also comes with heavy theoretical burdens. The first difficulty that arises for this view is straightforwardly borne out by the TWO LONDONS case: to which of the two Londons should George be committed? Which hinges are the right hinges? There are two ways to go about this: one option is to take George to only have entitlement for the hinges corresponding to one particular point in time (and the corresponding scenario). On this view, George will have entitlement for London \#1 hinges at $\mathrm{t} 1$, and, respectively, for London \#2 hinges at $\mathrm{t} 2$. This way to go, however, is extremely counterintuitive. First, it clashes with the intuition that, at best, he should only buy into one scenario and suspend on the other. Second, it generalizes in ugly ways: if whenever we have seemings that seem to come in conflict with certain facts that we previously took ourselves to know about the world, we are entitled to embrace them with confidence, it seems to follow that if I have an experience as of a pink elephant eating an ice-cream in my office while writing this paper, I am entitled to form the corresponding beliefs. ${ }^{12}$

\footnotetext{
10 For some representative articulations of this view, see for example Wright (2004) and (2007).

11 For a recent defence of a variation on this view, see Coliva (2015).

12 The counterintuitiveness of this kind of result has been discussed elsewhere in the literature on phenomenal conservativism (e.g., Huemer 2001), where specifically being committed to this kind of a permissive result is thought to be a reason to reject phenomenal conservativism.
} 
Option two, which also fits better with the view as stated, would be to claim that George should maintain his commitment to not being radically deceived all the way through (after all, what Pritchard calls 'the uber hinge' is perfectly general, it goes something along the lines of: 'I am not radically deceived'). This, however, again, clashes with the intuition that, at best, he should only buy into one scenario and suspend on the other. Furthermore, note that, intuitively and according to No-Belief, belief implies commitment: after all, for all the view has said so far, commitments are mere normatively botched beliefs, as it were: were they to be responsive to regular justifiers, they would be beliefs. If that is the case, there is more than intuitive inadequacy at stake when it comes to George's commitment to both Londons: first, depending on how the relevant hinges are construed, the view will likely deliver the result that George epistemically ought to have contradictory commitments. He ought to, for instance, be committed to the conjunction of $p$ : 'I am not being deceived at $\mathrm{t} 1$ (London \#1),' and $q$ : 'I am not deceived at $\mathrm{t} 2$ (London \#2),' while, at the same time, being (at least) permitted to believe that $r$ : $p$ implies non- $q$. Since, in turn, belief implies commitment, George would end up with contradictory commitments.

Even more problematically, contradictory commitments will either do grounding work for contradictory beliefs, or not do any grounding work at all. And here is why: it should be uncontroversial that George is confronted with very serious defeat in TWO LONDONS. Now, the champion of the refurbished No-Belief view will have two options: either she has to say that primary epistemic permissibility overrides epistemic defeat, or that it does not.

If it does, George will end up with contradictory beliefs: given that he is supposed to be committed to not being deceived about either London \#1 or London \#2, George seems to have reason to believe, at the same time, that he has always been rich and that he has always been poor, that he has a very happy marriage and that he does not have one etc. This result, of course, is better avoided: while contradictory commitments for the sake of productivity of inquiry may be easier to swallow, contradictory beliefs will just be inquiry underminers: all motivation for the view seems to be lost.

The alternative, of course, is to keep primary epistemic permissibility and gardenvariety, knowledge-generating epistemic permissibility apart. On this version of the view, although George has primary permissibility for being committed to both London \#1 and London \#2, his justification for believing the details of the two scenarios is defeated. On the bright side, this version of the view does not deliver permissible contradictory beliefs. Unfortunately, however, it loses motivation. To see this, note first that, if all everyday beliefs that George entertains are unjustified in virtue of generalised defeat, the commitments to the London \#1 and, respectively, London\#2 hinges are not doing any work: there is no successful inquiry that they are grounding. George is primarily permitted to believe the hinges, but has no epistemic justification for any of the everyday beliefs.

Now, of course, the champion of refurbished No-Belief need not be very impressed by the unfortunate predicament of poor George: after all, hinge commitments are not by definition epistemically functional: they are necessary preconditions for getting started in inquiry, not a guarantee that such inquiry will get off the ground. Sometimes, the thought would go,- - such as in the case of George above - things just go very badly, although hinges are in place. 
The problem with this way of thinking about what is going on in TWO LONDONS is that the view, such construed, loses much of its anti-sceptical appeal. After all, if rising the sceptical hypothesis generates defeaters for all of our everyday beliefs-a point that has been defended on various kinds of grounds ${ }^{13}$ — and anti-sceptical hinge commitments can do nothing to help us with this situation-because on this version of the view, they do not override defeat - this hinge epistemology fails to do the precise anti-sceptical work that hinge epistemologies are in the market of doing.

\section{Conclusion}

We have assessed the normative credentials of moving from doxastic normativism to a No-Belief hinge epistemology. We have argued for two varieties of pessimism about this move; motivation pessimism and theoretical fruitfulness pessimism. In a nutshell, if we're right, even if doxastic normativism is true, we have little in the way of theoretical reasons to believe that we are mistaken about our attitudes towards hinge propositions: they are garden-variety beliefs. No-Belief remains unmotivated. What's more, we have shown that embracing a No-Belief view will either get us in serious theoretical trouble, or loose all anti-sceptical appeal.

Open Access This article is distributed under the terms of the Creative Commons Attribution 4.0 International License (http://creativecommons.org/licenses/by/4.0/), which permits unrestricted use, distribution, and reproduction in any medium, provided you give appropriate credit to the original author(s) and the source, provide a link to the Creative Commons license, and indicate if changes were made.

\section{References}

Coliva, A. (2015). Extended rationality: A hinge epistemology. Berlin: Springer.

DeRose, K. (1995). Solving the skeptical problem. The Philosophical Review, 104(1), 1-52.

Glüer, K., \& Wikforss, Å. (2009). Against content normativity. Mind, 118(469), 31-70.

Huemer, M. (2001). Skepticism and the veil of perception. Lanham: Rowman \& Littlefield.

McDowell, J. (1996). Mind and world. Cambidge: Harvard University Press.

Moyal-Sharrock, D. (2013). On Coliva's judgmental hinges. Philosophia, 41(1), 13-25.

Olson, J. (2011). Error theory and reasons for belief. In Andrew Reisner \& Asbjørn Steglich-Petersen (Eds.), Reasons for belief. Cambridge: Cambridge University Press.

Pollock, J. L. (1986). Contemporary theories of knowledge. Lanham: Rowman \& Littlefield.

Pritchard, D. (2010). Relevant alternatives, perceptual knowledge and discrimination. Noûs, 44(2), $245-268$.

Pritchard, D. (2015). Epistemic Angst: Radical skepticism and the groundlessness of our believing. Princeton: Princeton University Press.

Shah, N., \& Velleman, J. D. (2005). Doxastic deliberation. The Philosophical Review, 114(4), 497-534.

Streumer, B. (2013). Can we believe the error theory? The Journal of Philosophy, 110(4), 194-212.

\footnotetext{
13 One route to this result is to argue, as DeRose (1995) does, that raising such possibilities alters the conversational context with reference to which the truth of knowledge ascriptions is sensitive. However, one needn't appeal to any kind of contextualist proposal in order to get the result that raisinge sceptical scenarios generates defeaters. One can get what is effectively the same result by appealing either (i) to ordinary thinking about the mechanisms of mental state defeaters (e.g., Pollock 1986); or (ii) to relevant alternatives theory (including non-contextualist varieties of this theory, according to which raising an error possibility makes that possibility 'live' and such that it must be rationally dismissed if the subject is to retain her knowledge of the target proposition). See, for example, Pritchard (2010).
} 
Wright, C. (2004) Warrant for nothing (and foundations for free)?. In Aristotelian Society Supplementary Volume (Vol. 78, No. 1, pp. 167-212). University College London: The Aristotelian Society.

Wright, C. (2007). Perils of Dogmatism. In S. Nuccetelli \& G. Seay (Eds.), Themes from GE Moore: New essays in epistemology (pp. 25-48). Oxford: Oxford University Press.

Publisher's Note Springer Nature remains neutral with regard to jurisdictional claims in published maps and institutional affiliations 